\title{
The effect of PI3K inhibitor LY294002 and gemcitabine hydrochloride combined with ionizing radiation on the formation of vasculogenic mimicry of Panc-1 cells in vitro and in vivo
}

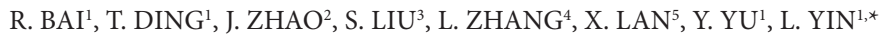

${ }^{1}$ Department of Radiotherapy, Dalian Municipal Central Hospital, Dalian, China; ${ }^{2}$ Department of Pathology, Dalian Municipal Central Hospital, Dalian, China; ${ }^{3}$ Department of Urology, Dalian Municipal Central Hospital, Dalian, China; ${ }^{4}$ Department of Central Laboratory, Dalian Municipal Central Hospital, Dalian, China; ${ }^{5}$ Department of Neurology, Dalian Municipal Central Hospital, Dalian, China

*Correspondence: ruiruikangkang@163.com

Received June 12, 2015 / Accepted August 27, 2015

\begin{abstract}
This research's purpose was to explore the existence of vasculogenic mimicry (VM) in both 3-D matrices of Panc-1 cells in vitro and orthotopic Panc-1 xenografts in vivo and to test the hypothesis that PI3K inhibitor LY294002 and gemcitabine hydrochloride would offer clear treatment benefit when integrated into ionizing radiation (IR) therapeutic regimens for treatment of pancreatic cancer. We explored the existence of VM in both 3-D matrices of Panc-1 cells and orthotopic Panc-1 xenografts. We subsequently investigated the activation of the PI3K/MMPs/Ln-5 2 signaling pathway in response to IR. LY294002 and gemcitabine hydrochloride were then evaluated for their radiosensitizing effect solely and in combination. We found that VM existed in both 3-D matrices of Panc-1 cells in vitro and orthotopic Panc-1 xenografts in vivo. The expressions of p-Akt and MMP- 2 were found to increase in response to IR. LY294002 and gemcitabine hydrochloride combined with IR better inhibited cell migration, VM formation and MMP-2 mRNA expression of Panc-1 cells in vitro, and we also proved that the novel therapeutic regimen better inhibited tumor growth, tumor metastasis and VM formation of orthotopic Panc-1 xenografts by suppressing the PI3K/MMPs/Ln-5 $\gamma 2$ signaling pathway in vivo. Our present study is among the first to prove the VM formation in orthotopic Panc-1 xenografts. Furthermore, our current study is also among the first to provide preliminary evidence for the use of the novel therapeutic regimen LY294002 and gemcitabine hydrochloride combined with IR for treatment of pancreatic cancer.
\end{abstract}

Key words: pancreatic cancer, vasculogenic mimicry, ionizing radiation, PI3K, gemcitabine hydrochloride, radiosensitization

In the Western world, pancreatic cancer is the fourth leading cause of cancer-related deaths [1]. It is one of the most aggressive tumors with an overall 5-year survival rate of fewer than 5\% mainly because of its highly aggressive characteristic, early metastasis, and resistance to existing radiotherapy and chemotherapy $[2,3]$. However, the underlying mechanism of pancreatic cancer progression is poorly understood till now [4]. As we all know, rich blood supply is a prerequisite for the rapid growth of tumor, thus, anti-angiogenic therapy has become one of the hotspots of cancer treatment, but its effect is unsatisfactory.

An effective microcirculation is necessary for the growth and metastasis of tumors, and a tumor microcirculation consists of vasculogenesis, angiogenesis and vasculogenic mimicry (VM). VM was first described by Maniotis et al [5] in
1999. VM refers to channel structure which is not composed of endothelial cells but of tumor cells and it can conduct plasma and blood cells. High VM formation abilities are often associated with poor prognosis and highly aggressive $[6,7]$. As an important complement to the tumor angiogenesis theory, VM may provide a reasonable explanation of ineffective antiangiogenic therapy for cancer patients. VM has been observed in a variety of aggressive tumors including cancers (such as bladder cancer, prostate cancer, ovarian cancer, lung cancer, breast cancer and renal cancer), sarcomas (such as mesothelial sarcoma, Ewing's sarcoma, osteosarcoma, synovial sarcoma and alveolar rhabdomyosarcomas), glioblastoma, glioma and astrocytoma [8]. Recently, Xu XD et al [9] and Guo JQ et al [10] have reported that VM can also be observed in pancreatic cancer. It has been reported that PI3K/MMPs/Ln-5 22 signal- 
ing pathway plays a major role in the formation of VM [11], and VM can be inhibited by suppressing the PI3K/MMPs/ Ln-5 $\gamma 2$ signaling pathway in various tumors [12-14].

The standard of care for early-stage pancreatic cancer is primary resection and subsequent adjuvant chemotherapy, while the advanced-stage pancreatic cancer patients' treatment options are controversial, which include neoadjuvant therapy with subsequent resection, extended surgical resection or palliative radiotherapy and/or chemotherapy [15]. Radiotherapy, which is the medical use of ionizing radiation (IR), has been proven as a basic tool available for the fight against cancer. Because it mainly affects the cells and tissues which are situated inside the beam of IR, it can be considered a non-invasive local treatment [16]. However, as one of the basic treatments of advanced-stage pancreatic cancer, the efficacy of radiotherapy is unsatisfactory [17]. Gemcitabine hydrochloride is presently considered one of the most active, well-accepted conventional agents in pancreatic cancer [18] and several studies have shown that it has been used as a radiosensitization for pancreatic cancer in clinic [19, 20]. 2-(4-morpholinyl)-8-phenylchromone (also known as 2-morpholino-8-phenyl-4H-1-benzopyran-4one, LY294002), an analogue of quercetin which is synthesized artificially, can specifically and completely eliminate the activity of PI3K [21]. Many studies also have shown that the antitumor effect of gemcitabine hydrochloride in pancreatic cancer is reinforced by the inhibition of PI3K $[3,18,22]$. However, it's difficult to achieve satisfactory therapy effect by applying these treatments alone currently, thus we consider to examine whether PI3K inhibitor LY294002 and gemcitabine hydrochloride combined with IR could have better effect on pancreatic cancer.

In this study, we explored the formation of VM in both 3-D matrices of Panc-1 cells in vitro and orthotopic Panc-1 xenografts in vivo, and also investigated the activation of $\mathrm{PI} 3 \mathrm{~K} /$ MMPs/Ln-5 $\gamma 2$ signaling pathway in response to IR both in vitro and in vivo. Furthermore, we verified the hypothesis that LY294002 and gemcitabine hydrochloride would offer clear treatment benefit when integrated into IR therapeutic regimens for treatment of pancreatic cancer.

\section{Materials and methods}

Chemical and reagents. LY294002 (Purity $\geq 99 \%$ ) was purchased from Selleck Chemicals (Houston, TX, USA). Gemcitabine hydrochloride was purchased from Ely Lilly (Bad Homburg, Germany). Matrigel was obtained from BD Biosciences (San Jose, CA, USA). Anti-CD31 and antiMMP-2 antibodies were purchased from Santa Cruz Biotech (San Jose, CA, USA). Anti-Akt and anti-p-Akt (Ser 473) antibodies were obtained from Cell Signaling Tech (Beverly, MA, USA). RPMI 1640, fetal bovine serum (FBS), penicillin $\mathrm{G}$, streptomycin, trypsin and $0.1 \mathrm{M}$ phosphate buffered saline (PBS) were purchased from Invitrogen (Grand Island, NY, USA). Immunohistochemistry SABC kit and the liquid diaminobenzidine (DAB)+ Substrate Chromogen System-
HRP used for immunohistochemistry were obtained from Zhongshan Golden Bridge Biotechnology co., Ltd (Beijing, China). Hematoxylin stain, eosin stain, $0.5 \%$ periodic acid and Schiff solution were provided by Pathology of Dalian Municipal Central Hospital (Dalian, China). TRIzol reagent was purchased from Invitrogen (Grand Island, NY, USA). RevertAid First Strand cDNA Synthesis Kit was obtained from Fermentas (South Logan, UT, USA). SYBR-Green real-time PCR master mix-plus was purchased from Toyobo (Japan). 3-(4,5-dimethylthiazol-2-yl)-2,5-diphenyltetrazolium bromide (MTT), DMSO, coomassie brilliant blue (CBB) R250 and EDTA were obtained from Sigma Chemical (St. Louis, MO, USA). Chloral hydrate, paraformaldehyde and TritonX-100 were obtained from Wuhan Life Technology co., Ltd (Wuhan, China). Isoflurane was purchased from Shenzhen RWD Life Science co., Ltd (Shenzhen, China).

Cell culture. Human pancreatic cancer cell line Panc-1 was purchased from Beijing Bamboo Biotechnology co., Ltd (Beijing, China). Human breast cancer cell line MCF-7 was provided by Central Laboratory of Dalian Municipal Central Hospital (Dalian, China). Cells were cultured in RPMI-1640 medium supplemented with $15 \%$ fetal bovine serum, $100 \mathrm{U} / \mathrm{ml}$ of penicillin $\mathrm{G}$ and $100 \mu \mathrm{g} / \mathrm{ml}$ of streptomycin and incubated at $37^{\circ} \mathrm{C}$ with $5 \% \mathrm{CO}_{2}$ and humidity. The culture medium was changed every 2 days.

Experimental radiation. IR was performed with an Elekta medical linear accelerator (The Sweden Elekta Inc., Sweden). $6 \mathrm{MV} \mathrm{X}$-ray was applied to both in vitro and in vivo experiments. For in vitro experiments, a $20-24 \mathrm{~cm}^{2}$ cone was used at a source-to-surface distance (SSD) of $100 \mathrm{~cm}$ at a dose rate of approximately $300 \mathrm{cG} / \mathrm{min}$. Before applying IR, a piece of "solid water" which was about $1 \mathrm{~cm}$ thick was placed on the surface of 6-multiwell, 24-multiwell or 96-multiwell plate. For in vivo experiments, nude mice were anesthetized with isoflurane inhalation and then they were placed in fixed cardboard. A $6-8 \mathrm{~cm}^{2}$ cone was used at an SSD of $40 \mathrm{~cm}$ at a dose rate of approximately $300 \mathrm{cGy} / \mathrm{min}$.

Proliferation assay. The effect of LY294002, gemcitabine hydrochloride or IR on cell proliferation was determined by using MTT cell proliferation assay. The Panc- 1 cells $(5,000$ per well) were incubated with or without LY294002, gemcitabine hydrochloride or IR in various doses, in triplicate in 96-well plate and then incubated for 24 hours, 48 hours or 72 hours at $37^{\circ} \mathrm{C}$ with $5 \% \mathrm{CO}_{2}$ individually. $50 \mu 15 \mathrm{mg} / \mathrm{mL}$ MTT tetrazolium salt dissolved in PBS was added to each well and then incubated for 4 hours at $37^{\circ} \mathrm{C}$. After centrifugation and removal of the medium, $150 \mu \mathrm{l} /$ well of DMSO was added to dissolve formazan crystals. The absorbance was measured using a microplate reader (Bio-Rad Laboratories, CA, USA) at a test wavelength of $490 \mathrm{~nm}$. Three experimental replicates were performed. The drug concentration or IR dose inducing $50 \%$ of cell growth inhibition (IC50) was calculated from the inhibition rate of cell proliferation curve. Dose of LY294002, gemcitabine hydrochloride or IR used in in vitro experiment was about $20 \%$ IC50. 
In vitro experimental protocol. There were 8 treatment groups ( $n=6$ per group): (a) DMSO: DMSO control $(9 \mu \mathrm{l}$ DMSO in 100ml complete medium), (b) IR: IR alone (X-ray, $2 \mathrm{~Gy}),(\mathrm{c}) \mathrm{G}$ : gemcitabine hydrochloride alone $(20 \mu \mathrm{M})$, (d) LY

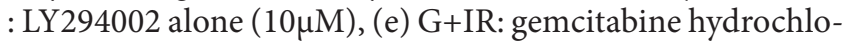
ride, $20 \mu \mathrm{M}$, and X-ray, $2 \mathrm{~Gy}$, (f) LY+IR: LY294002, 10 $\mu \mathrm{M}$, and $\mathrm{X}$-ray, 2Gy, (g) G+LY: gemcitabine hydrochloride, $20 \mu \mathrm{M}$, and

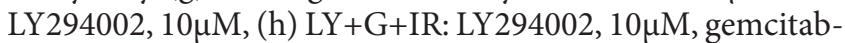
ine hydrochloride, $20 \mu \mathrm{M}$, and $\mathrm{X}-$ ray, $2 \mathrm{~Gy}$.

Cytoskeleton staining. The $8 \times 8 \mathrm{~mm}^{2}$ Poly-L-Lysine coated coverslips were put into 24-multiwell plate, and then 200 Panc- 1 cells were seeded into per well. After 24 hours, the cells were incubated with 8 kinds of different treatments respectively for 48 hours at $37^{\circ} \mathrm{C}$ with $5 \% \mathrm{CO}_{2}$. After washing with PBS, the cells were fixed for 5 seconds with $2 \%$ paraformaldehyde. At the end of the experiments, cell membrane was ruptured with $1 \%$ TritonX-100 at room temperature for 30 minutes and washed with PBS followed by fixation with $4 \%$ formaldehyde in PBS for 15 minutes. The cells were then stained with $0.2 \%$ CBB R250 for 40 minutes and washed with deionized water.

Wound-Healing assay. Panc- 1 cells were seeded at the density of $1 \times 10^{6}$ cells per well into 6 -multiwell plate and cultured in RPMI 1640 medium supplemented with 10\% FBS. At confluence, the cells at the bottom of culture plates were scraped off using a $200 \mu \mathrm{l}$ pipette tip to create a cell-free area. Then, the cells were cultured in serum-free RPMI 1640 medium. During this process, the cells were incubated with 8 kinds of different treatments respectively for 12 hours. At the 0 hour and 12 hour time point, Panc- 1 cells with scratch-wounds were observed by an inverted microscope and then IPP6.0 was used to measure the migration distance between the scratched line and the growing edge of the cells at five points. The migration index was expressed as the migration distance of treatment group/the migration distance of DMSO group $\times 100 \%$, which can reflect the effect of different treatment groups respectively on Panc- 1 cells' migration ability.

Three-dimensional cultures and in vitro network formation. $50 \mu \mathrm{l}$ Matrigel was dropped onto glass coverslip and allowed to polymerize for 1 hour at room temperature, then 30 minutes at $37^{\circ} \mathrm{C}[23] .3 \times 10^{5}$ tumor cells within $50 \mu \mathrm{l}$ complete medium were then seeded onto the Matrigel and incubated for 6 hours in a humidified atmosphere of 5\% $\mathrm{CO}_{2}$ at $37^{\circ} \mathrm{C}$. The cultures were incubated with 8 kinds of different treatments respectively. An inverted microscope was used to observe the formation of VM everyday, and the number of VM of different treatment groups was counted 2 days later. Two observers reviewed the cells independently to evaluate the VM formation of Panc-1 cells separately under the light microscopy and counted every VM of the selected ten low power fields $(\times 40)$, the average VM count of the ten fields was regarded as the final result.

Animals. Female athymic nu/nu mice (4-5 weeks old) were obtained from Dalian Medical University. The animals were housed in standard plastic cages (five per cage) inside a controlled ventilated rack; their diet consisted of autoclave chow and water ad libitum. All of the mice were tested pathogen free. Before experiments, all the mice were acclimated for 7 days in the laboratory. Tumor xenografts were carried out under general anesthesia obtained with $10 \%$ chloral hydrate intraperitoneal injection. Ionizing radiations were carried out under general anesthesia obtained with isoflurane inhalation. Our experimental protocol was reviewed and approved by the Institutional Animal Care and Use Committee of Dalian Medical University.

Orthotopic implantation tumor model. To produce the Panc- 1 donor tumors, $5 \times 10^{6}$ cells in $100 \mu$ l serum-free medium were injected subcutaneously into the left flank of nude mouse. Tumor sizes were measured 3 times weekly using a caliper. The orthotopic implantation tumor models were built as Ralph Graeser [24] previously described.

In vivo experimental protocol. One week after implantation, the orthotopic implantation pancreatic cancer models were randomized into 8 groups ( $n=6$ per group): (a) DMSO: DMSO control (5\%DMSO in PBS, $28 \mathrm{ml} / \mathrm{kg}$ once daily by i.p. injection), (b) IR: IR alone (X-ray 2Gy daily, 5 times weekly), (c) G: gemcitabine hydrochloride alone $(62.5 \mathrm{mg} / \mathrm{kg}$ [18] once every other day by i.p. injection), (d) LY: LY294002 alone (50 mg/ kg [18] once daily by i.p. injection), (e) G+IR: gemcitabine hydrochloride, $62.5 \mathrm{mg} / \mathrm{kg}$ once every other day by i.p. injection, and X-ray, 2Gy daily, 5 times weekly, (f) LY+IR: LY294002, 50 $\mathrm{mg} / \mathrm{kg}$ once daily by i.p. injection, and X-ray, 2Gy daily, 5 times weekly, (g) G+LY: gemcitabine hydrochloride, $62.5 \mathrm{mg} / \mathrm{kg}$ once every other day by i.p. injection, and LY294002, $50 \mathrm{mg} / \mathrm{kg}$ once daily by i.p. injection, (h) LY+G+IR: LY294002, $50 \mathrm{mg} / \mathrm{kg}$ once daily by i.p. injection, gemcitabine hydrochloride, $62.5 \mathrm{mg} / \mathrm{kg}$ once every other day by i.p. injection and X-ray, 2Gy daily, 5 times weekly. For combination treatment groups, LY294002 and/or gemcitabine hydrochloride were/was given 2 hours prior to IR exposure. All the experimental mice were treated with left upper abdominal palpation daily and weighed every other day. Therapies were continued for 2 weeks, and the animals were euthanized 2 weeks later. Preliminary evidence of distant metastasis was observed by exploring abdominal and thoracic organs. The metastasis rate was expressed as the number of nude mice that appeared distant metastasis/the number of nude mice in corresponding treatment group. Orthotopic xenografts in the pancreas and visible metastases in other organs were excised, and the final tumor volume was measured as $\mathrm{V}=($ Length $\times$ Width $\times$ Width) $/ 2$.

Hematoxylin and eosin staining. Both tumor tissue sections of $4 \mu \mathrm{m}$ and metastatic tumor tissue sections of $4 \mu \mathrm{m}$ were warmed up to $60^{\circ} \mathrm{C}$ for 2 hours and deparaffinized in xylene and rehydrated in series of alcohol. The sections were incubated with hematoxylin for 15 minutes and then decolored with $1 \%$ hydrochloric acid alcohol solution for 35 seconds. Next, the sections were incubated with eosin for 10 minutes and decolored with $90 \%$ ethanol for 40 seconds.

Immunohistochemistry and CD31/Periodic Acid Schiff (PAS) double staining. This assay was performed as described by Zhang et al [25] with some modifications. Tumor tissue 
sections of $4 \mu \mathrm{m}$ were warmed up to $60^{\circ} \mathrm{C}$ for 2 hours and deparaffinized in xylene and rehydrated in series of alcohol. Antigen was retrieved by $0.01 \mathrm{M}$ citric acid buffer (PH 6.0) microwave antigen retrieval at $98^{\circ} \mathrm{C}$ for 16 minutes. After 10 minutes cooling period, the sections were rinsed with PBS and endogenous peroxidase block was performed for 10 minutes in methanol containing 3\% hydrogen peroxide at room temperature. After rinsed with PBS, slides were blocked with recommended serum for 20 minutes at room temperature and incubated with a primary antibody (i.e., the anti-CD31 at a dilution of 1:100, anti-p-Akt at a dilution of 1:50, anti-Akt at a dilution of 1:200, or anti-MMP-2 at a dilution of 1:100) overnight at $4^{\circ} \mathrm{C}$ in a humidified box. The next day, the sections were rinsed with PBS for three times and incubated with a homologous secondary antibody for 1 hour at room temperature. At the end of the experiments, the slides were stained with dispensed DAB solution for 2-8 minutes in a dark room and then counterstained with hematoxylin. For CD31/ PAS double staining, the slides were incubated with $0.5 \%$ periodic acid for 15 minutes and then incubated with Schiff reagent for 15 minutes at room temperature between $\mathrm{DAB}$ staining and hematoxylin counterstaining. During this process, we used distilled water instead of PBS for washing. Two observers reviewed slides independently to evaluate the microvessel density (MVD) and vasculogenic mimicry density (VMD) of the orthotopic Panc-1 xenografts separately under the light microscopy. MVD was assessed with anti-CD31 immunohistochemical staining and evaluated in accordance with the method first described by Weidner et al [26]. Histologically, as described by Seftor RE et al [27], VM emerges as multiple, laminin-rich vasculature network which is surrounded by clusters of tumor cells and can be stained with PAS, while blood vessels can be stained with both PAS and CD31, we can distinguish between VM and blood vessels. The counting method of VMD was the same with MVD. IPP6.0 was used to analyze the expressions of p-Akt, Akt and MMP- 2 by measuring the mean optical density.

RNA isolation and Quantitative Real-Time reverse transcriptase Polymerase Chain Reaction (qRT-PCR). The expressions of MMP-2 mRNA both in vitro and in vivo were detected as Guo JQ et al [10] previously described. The genespecific primers were shown in Table 1. GAPDH was used as internal reference gene. Total RNA from Panc-1cell lines or orthotopic xenograft tissues was isolated using TRIzol reagent according to the manufacturer's instructions. RNA from each sample was then reverse transcribed into cDNA using

Table 1. Primer sequences and PCR products size.

\begin{tabular}{lll}
\hline Gene & Primers & Size of PCR products (bp) \\
\hline MMP-2 & 5'-gatacccctttgacggtaagga-3' & 112 \\
& 5'-ccttctcccaaggtccatagc-3' & \\
GAPDH & 5'-gagtcaacggatttggtcgt-3' & 238 \\
& 5'-ttgattttggagggatctcg-3' & \\
\hline
\end{tabular}

RevertAid First Strand cDNA Synthesis Kit according to the manufacturer's protocol. PCR amplification was performed using gene-specific primers in a Roche real-time PCR machine. The PCR amplifications included the following conditions: $95^{\circ} \mathrm{C}$ for 90 seconds and 40 cycles of $95^{\circ} \mathrm{C}$ for 5 seconds, $60^{\circ} \mathrm{C}$ for 30 seconds, and $72^{\circ} \mathrm{C}$ for 45 seconds. The experiments were performed in triplicates and repeated three times. The data were analyzed using LinRegPCR software. The data were
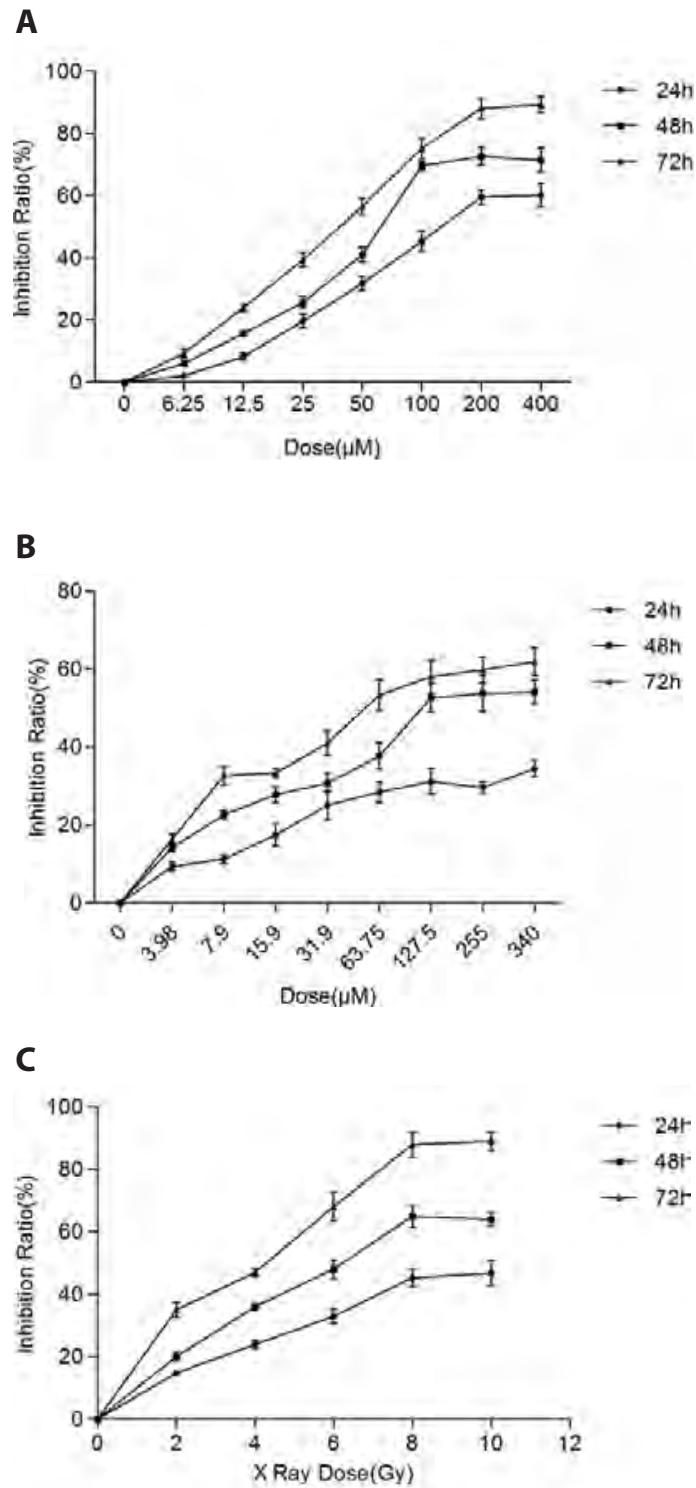

Figure 1. The MTT cell proliferation assays. A) Inhibition of LY294002 on Panc-1 cells and the dose-response curves of LY294002 effect on Panc-1 cells for 24 hours, 48 hours or 72 hours, the IC50 value is $62.35 \mu \mathrm{M}$ for 48 hours. B) Inhibition of gemcitabine hydrochloride on Panc-1cells and the dose-response curves of gemcitabine hydrochloride effect on Panc-1 cells for 24 hours, 48 hours or 72 hours, the IC50 value is $117.94 \mu \mathrm{M}$ for 48 hours. C) Inhibition of IR on Panc-1 cells and the dose-response curves of IR effect on Panc- 1 cells for 24 hours, 48 hours or 72 hours, the IC50 value is $6.17 \mathrm{~Gy}$ for 48 hours. 
normalized using cycle threshold $(\mathrm{Ct})$ value corresponding to GAPDH. The relative expressive level of MMP-2 mRNA was calculated using the $2^{-\Delta \Delta \mathrm{Ct}}$ method.

Statistical analysis. The SPSS 19.0 statistical package was used for all calculations. The data shown in this study represented the mean \pm S.E. The values were initially subjected to one-way ANOVA and then later compared among groups with q test. Repeated measures ANOVA was used to analyze the variation of nude mice' body weights. The differences between groups were considered to be statistically significant when the $p$ value was $<0.05$ or the $p$ value was $<0.01$.

\section{Results}

LY294002, gemcitabine hydrochloride or IR inhibits the proliferation of Panc-1 cells. The influence of LY294002, gemcitabine hydrochloride or IR on Panc-1 cells' proliferation was determined using the MTT assay in vitro. As shown in Figure 1A, 1B and 1C, LY294002, gemcitabine hydrochloride or IR inhibited the proliferation of Panc-1 cells in a dose-dependent manner, and their IC50 values of 48 hours were $62.35 \mu \mathrm{M}$, $117.94 \mu \mathrm{M}$ and $6.17 \mathrm{~Gy}$.
LY294002 in combination with gemcitabine hydrochloride sensitizes Panc-1 cells to IR in vitro. IR promotes the migration of Panc-1 cells, while concurrent treatment with LY294002, gemcitabine hydrochloride and IR inhibits the migration of Panc-1 cells. The effect of 8 different kinds of treatments on cell migration was tested respectively through wound-healing assay in vitro. Interestingly, results in Figure $2 \mathrm{~A}$ and $2 \mathrm{~B}$ demonstrated that IR promoted the "gap" closing; this promotion could be eliminated by combining IR with LY294002 and/or gemcitabine hydrochloride. LY+G+IR group suppressed the "gap" closing, indicating its inhibitory efficiency against Panc-1 cells migration in vitro. As no significant cell viability change was observed after 8 different kinds of treatments, respectively, for 12 hours, the promoted effect of IR and inhibitory effects of the remaining 6 different kinds of treatments, respectively, on cell migration were not secondary to increased or decreased viability.

Concurrent treatment with LY294002, gemcitabine hydrochloride and IR damages cytoskeleton and changes morphology of Panc-1 cells in vitro. Results in Figure 2C showed that the cytoskeleton of Panc-1 cells suffered different degrees of damage after incubating with 7 different kinds of treatments for

A
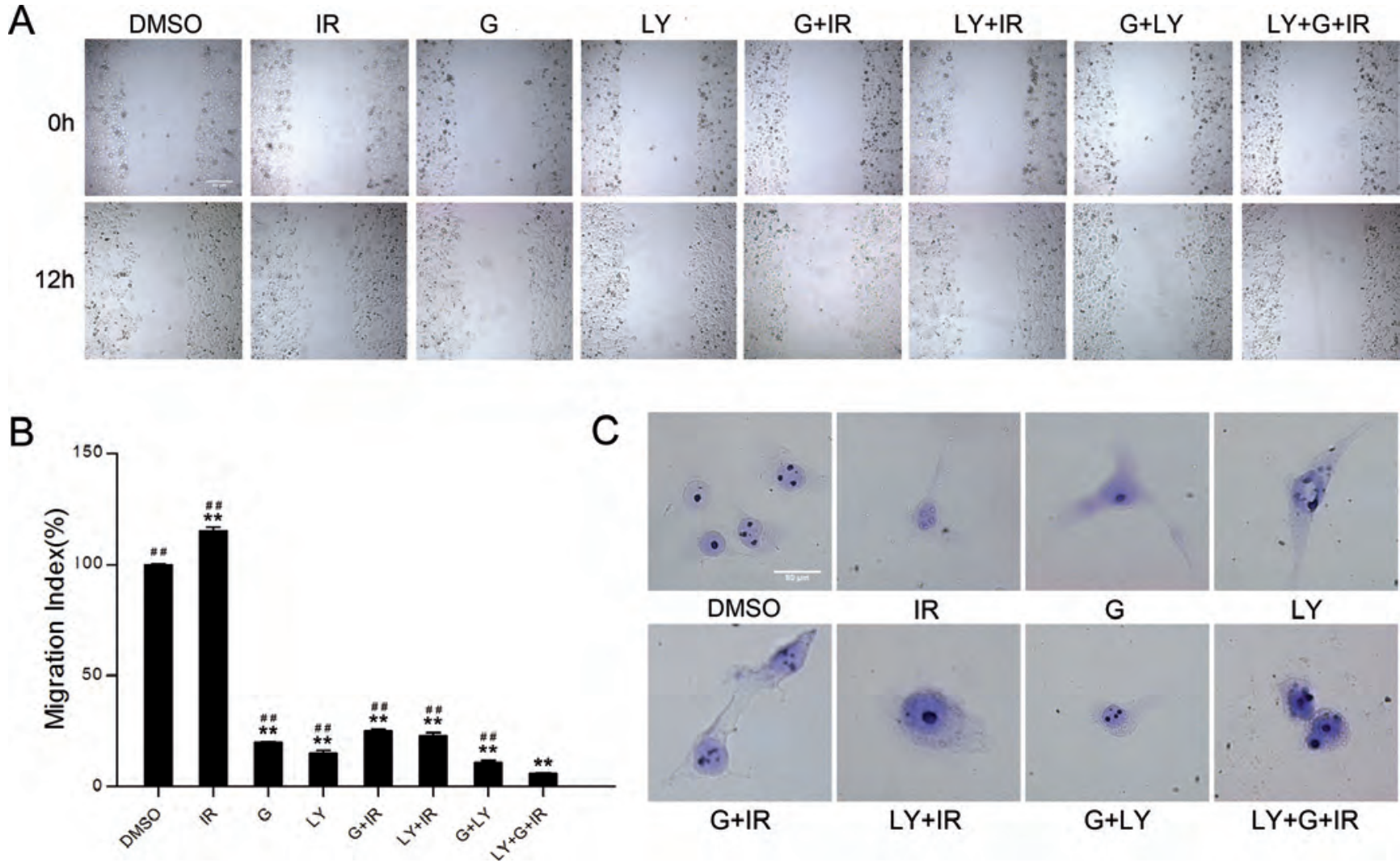

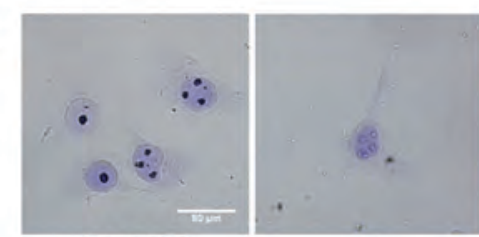

DMSO

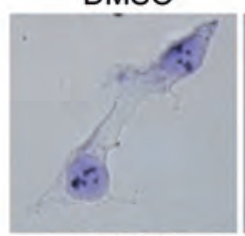

G+IR
IR

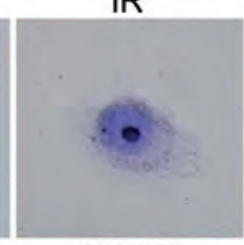

$L Y+I R$

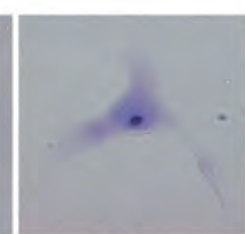

G

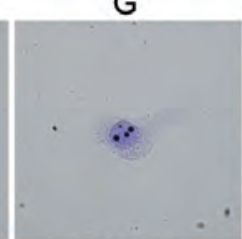

$\mathrm{G}+\mathrm{LY}$

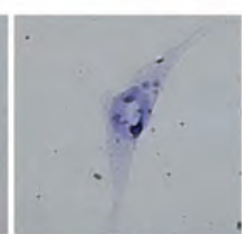

LY

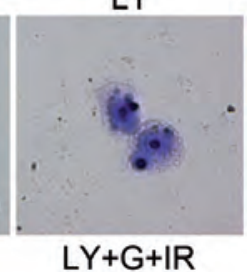

Figure 2. The migration and morphology of Panc-1 cells in different treatment groups. A) The effect of 8 different kinds of treatments, respectively, on Panc-1 cells' migration at $0 \mathrm{~h}$ and $12 \mathrm{~h}(\times 40)$. B) IR promoted the "gap" closing, while the remaining 6 different kinds of treatments suppressed the "gap" closing compared with DMSO group, respectively $\left({ }^{* *} p<0.01\right.$ ), and LY+G+IR group showed the strongest inhibitory effect (\# \# $p<0.01$ ). C) Damage of cytoskeleton and changes of morphology of Panc- 1 cells in different treatment groups $(\times 400)$. 
48 hours compared with DMSO group, respectively, and the morphology of Panc-1 cells were also changed in various degrees. Notably, the most obvious damage of cytoskeleton and changes of morphology were observed in LY+G+ IR group.

Concurrent treatment with LY294002, gemcitabine hydrochloride and IR suppresses the VM formation of Panc-1 cells in vitro. VM of tumor cells refers to aggressive cancer cells' plasticity in forming de novo vascular networks, which can contribute to the perfusion of rapidly growing tumors [28]. The MCF-7 cells' network formation assay was performed in vitro as a positive control (Figure $3 \mathrm{~A}$ ). We also observed the VM formation of human pancreatic cancer Panc-1 cells in vitro
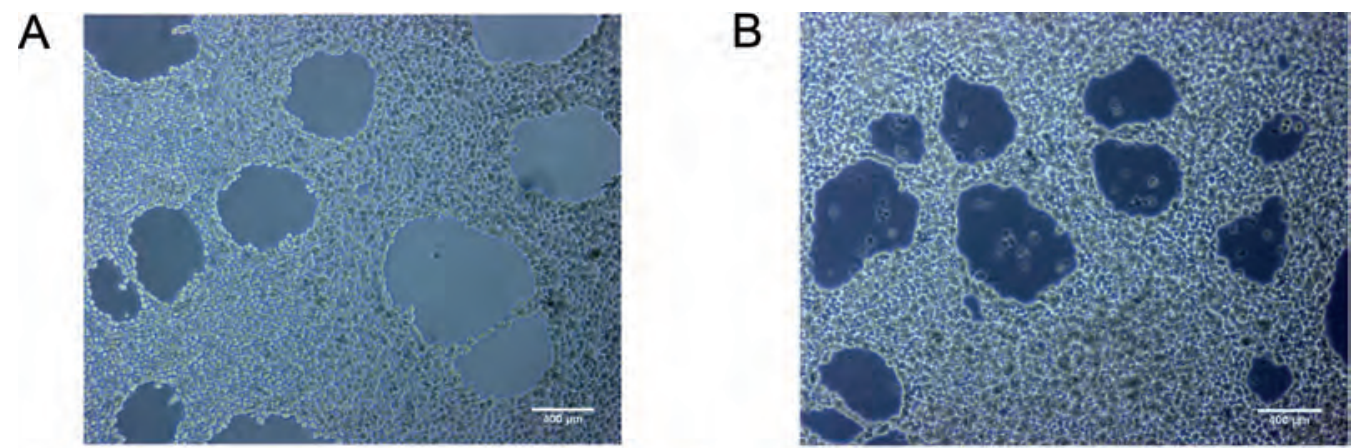

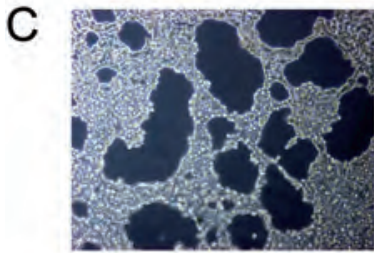

DMSO

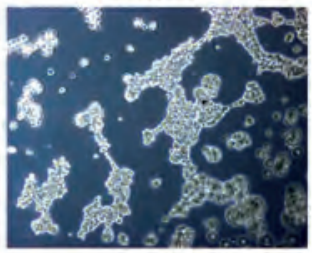

$\mathrm{G}+\mathrm{IR}$

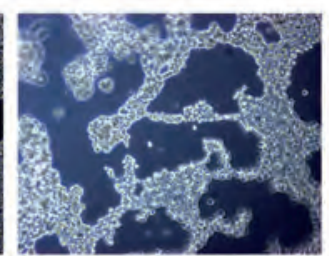

IR

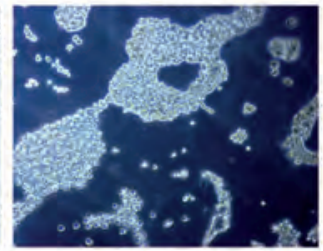

$\mathrm{LY}+\mathrm{IR}$

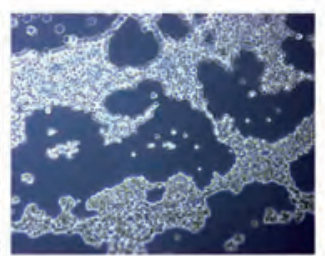

G

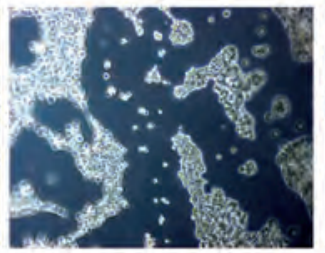

G+LY

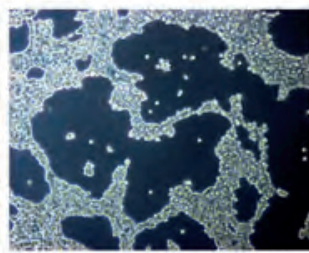

LY

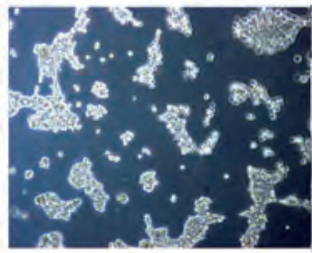

$L Y+G+I R$
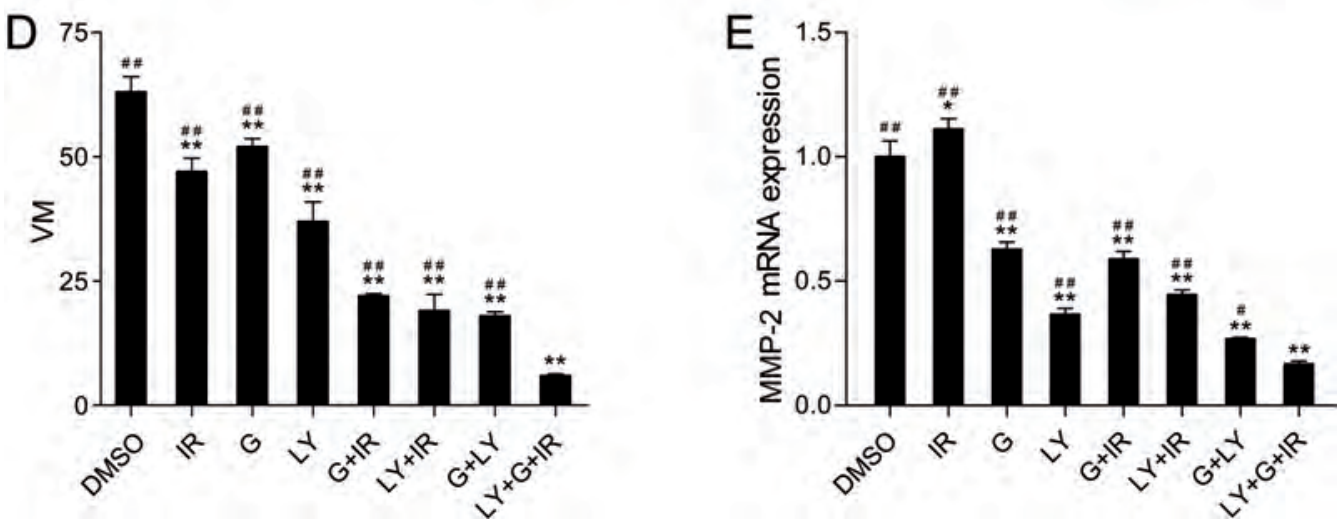

Figure 3. The VM formation and MMP-2 mRNA expression of Panc- 1 cells in different treatment groups in vitro. A) The VM formation of MCF-7 cells $(\times 100)$. B) The VM formation of Panc-1 cells $(\times 100)$. C) The VM of Panc-1 cells suffered different degrees of disruption after incubating with 7 different kinds of treatments, respectively, for 48 hours compared with DMSO group $(\times 100)$. D) All 7 different kinds of treatments appeared statistically significant inhibition on Panc-1 cells' VM formation compared with DMSO group, respectively $\left({ }^{*} p<0.01\right), \mathrm{LY}+\mathrm{G}+\mathrm{IR}$ group showed the strongest inhibitory effect $(\# \# p<0.01)$. E) Comparing with DMSO group, IR promoted MMP-2 mRNA expression of Panc-1 cells, while the remaining 6 different kinds of treatments suppressed MMP-2 mRNA expression of Panc-1 cells, respectively $\left({ }^{*} p<0.05\right.$ or $\left.{ }^{* *} p<0.01\right)$, and $\mathrm{LY}+\mathrm{G}+\mathrm{IR}$ group showed the strongest inhibitory effect $(\# p<0.05$ and $\# \# p<0.01)$. 
(Figure 3B). The VM of Panc-1 cells suffered different degrees of disruption after incubating with 7 different kinds of treatments, respectively, for 48 hours compared with DMSO group. Note that concurrent treatment with LY294002, gemcitabine hydrochloride and IR almost completely disrupted VM of Panc- 1 cells, more importantly, this novel treatment regimen showed the strongest inhibitory effect (Figure 3C and 3D).

IR promotes the expression of MMP- 2 MRNA in Panc- 1 cells in vitro, while concurrent treatment with LY294002, gemcitabine hydrochloride and IR downregulates it. As shown in Figure 3E, the expression of MMP-2 mRNA in Panc- 1 cells was promoted by IR, while all the remaining 6 treatments downregulated it compared with DMSO group, respectively. Moreover, concurrent treatment with LY294002, gemcitabine hydrochloride and IR showed the strongest inhibition.

LY294002 in combination with gemcitabine hydrochloride sensitizes Panc-1 cells to IR in orthotopic Panc-1 xenografts in vivo. Concurrent treatment with LY294002, gemcitabine hydrochloride and IR suppresses tumor growth in orthotopic Panc-1 xenografts in vivo. As shown in Figure $4 \mathrm{~A}$ and $4 \mathrm{~B}$, all 7 different kinds of treatments appeared statistically significant tumor growth inhibition in nude mice models in vivo compared with DMSO group, respectively. Tumor growth was significantly inhibited in LY+G+IR group compared with other 7 remaining kinds of treatments, respectively. However, it worth noting that the nude mice were well-tolerated with no obvious loss of body weight (Figure. 4C). Taken all together, our results demonstrated that LY294002 in combination with gemcitabine hydrochloride had strong actions on sensibilization of IR, as assessed in both cell cultures in vitro and orthotopic Panc-1 xenografts in vivo.

Concurrent treatment with LY294002, gemcitabine hydrochloride and IR suppresses tumor metastasis in orthotopic Panc-1 implantation tumor models in vivo. We had found that there were intestine, mesenteric lymph nodes, subcutaneous, inguinal lymph nodes, adrenal gland or stomach metastases in some orthotopic implantation tumor models. As shown in Figure $4 \mathrm{D}$, administration of IR alone didn't have any inhibitory effect on tumor metastasis. The remaining 6 different kinds of treatments appeared obvious anti-tumor metastasis activity in nude mice models in vivo compared with DMSO group, respectively. Tumor metastasis was significantly inhibited in $\mathrm{LY}+\mathrm{G}+\mathrm{IR}$ group compared with the remaining 7 different kinds of treatments respectively.

Concurrent treatment with LY294002, gemcitabine hydrochloride and IR suppresses MVD and VMD in orthotopic Panc-1 xenografts in vivo. As shown in Figure 5A, the number of CD31 positive microvessels (the structures stained by brown) in orthotopic Panc-1 xenografts treated with 7 different kinds of treatments showed decrease compared with DMSO group, respectively. All 7 different kinds of treatments were statistically significant compared with DMSO group, respectively, LY+G+IR group displayed statistically significant reduction in MVD compared with the remaining 7 different kinds of treatment groups, respectively (Figure 5C). We could see VM which was CD31 negative and PAS positive structure (red arrow) in Figure 5B. All 7 different kinds of treatments appeared statistically significant inhibition of VMD in orthotopic Panc-1 xenografts compared with DMSO group, respectively. VMD was significantly inhibited in LY+G+IR group compared with the remaining 7 different kinds of treatments, respectively (Figure 5D).

IR promotes the expressions of VM signaling-related markers $p$-Akt and MMP-2 in orthotopic Panc-1 xenografts in vivo, while concurrent treatment with LY294002, gemcitabine hydrochloride and IR downregulates these markers. To investigate the underlying mechanisms of concurrent treatment with LY294002, gemcitabine hydrochloride and IR inhibition on tumor growth and VM formation of pancreatic cancer, we explored the regulation effect of the novel treatment regimen on the PI3K/MMPs/Ln-5 $\gamma 2$ signaling pathway, i.e., the expressions of VM signaling-related markers, p-Akt, Akt and MMP-2 at protein level in orthotopic Panc-1 xenografts by immunohistochemistry, and the expression of MMP-2 mRNA in orthotopic Panc-1 xenografts by qRT-PCR. As shown in Figure 6, we found that the expressions of Akt proteins in 8 groups were consistent, the expressions of $\mathrm{p}$-Akt , MMP-2 proteins and MMP-2 mRNA in IR treatment group were significantly increased compared with DMSO group, while the expressions of these markers in the remaining 6 different kinds of treatment groups were significantly downregulated compared with DMSO group, respectively. Notably, the expressions of p-Akt, MMP-2 proteins and MMP-2 mRNA in LY+G+IR group were also significantly downregulated compared with the remaining 7 different treatment groups, respectively.

\section{Discussion}

As a new blood supply system, VM was first described by Maniotis et al [5] in 1999. VM is a channel composed of extracellular matrix and lined externally by tumor cells. Red blood cells and plasma can flow through the channel. Xu XD et al [9] have demonstrated that Panc-1 cells can form VM in 3-D matrices in vitro, while Guo JQ et al [10] have shown no VM formation in 3-D matrices of Panc-1 cells in vitro. Our present study demonstrated that VM existed in both Panc-1 cells' 3-D matrices in vitro and orthotopic Panc-1 xenografts in vivo. It's worth mentioning that our current study is among the first to prove the VM formation in orthotopic Panc-1 xenografts.

Because of its highly aggressive characteristic, early metastasis, disappointing surgical resection, resistance to existing chemotherapy and radiotherapy and poor prognosis of the patients with pancreatic cancer, novel adjuvant therapies and therapeutic regimens are clearly needed to treat this disease $[2,3]$. A tumor microcirculation consists of vasculogenesis, angiogenesis and VM. The traditional antiangiogenic therapies mainly target endothelial cells. Recent studies have demonstrated that the benefits of anti-angiogenesis therapy have far been rather modest and it may not be effective only to block angiogenesis [29-31]. VM is a special blood supply 
A
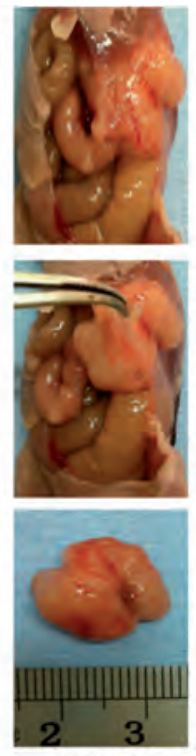

DMSO
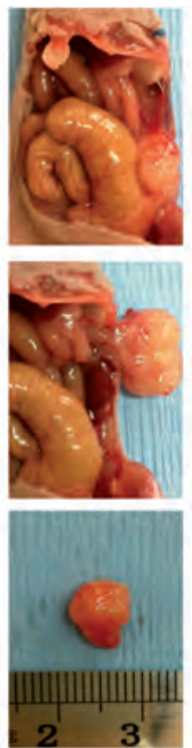

IR
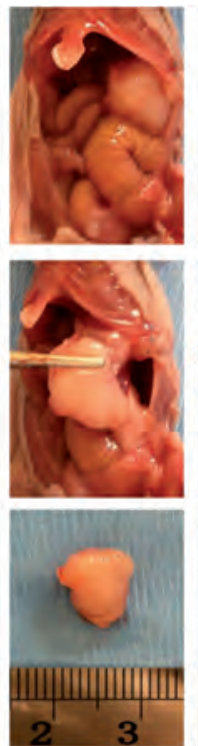

G
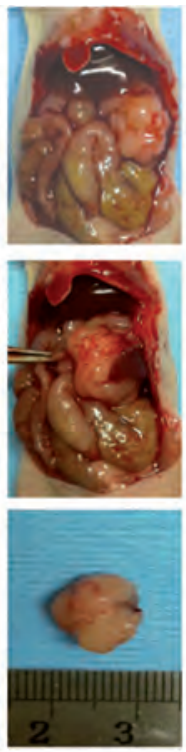

LY
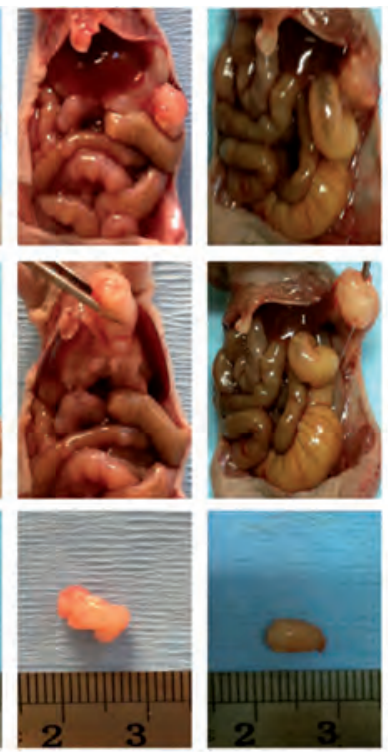

G+IR
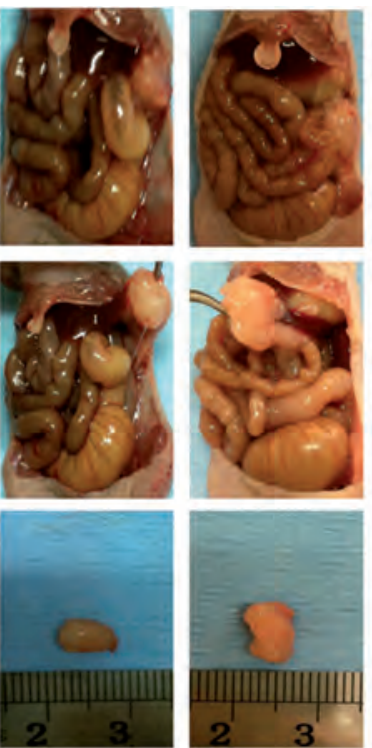

LY+IR

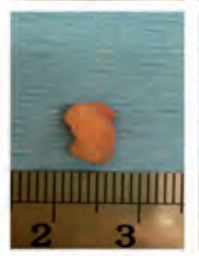

G+LY
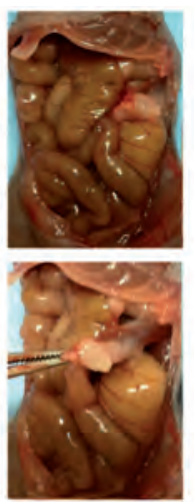

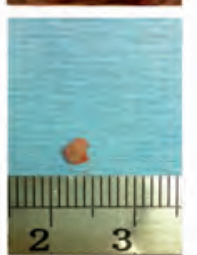

$L Y+G+I R$

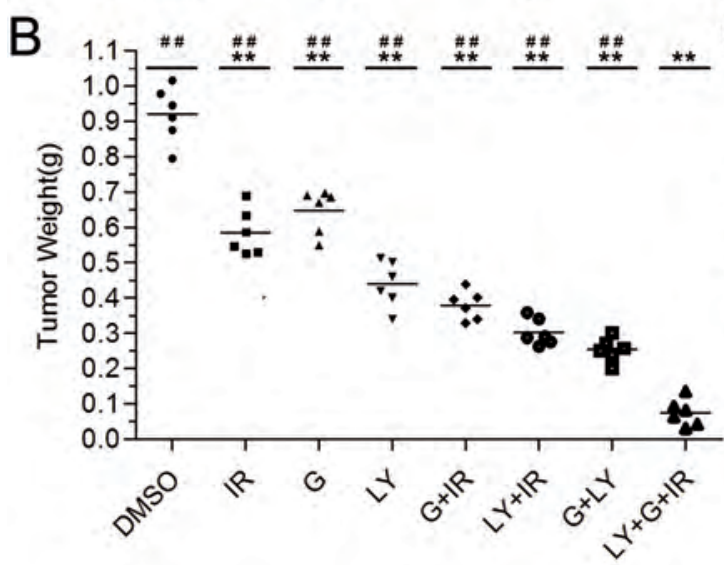

C 30
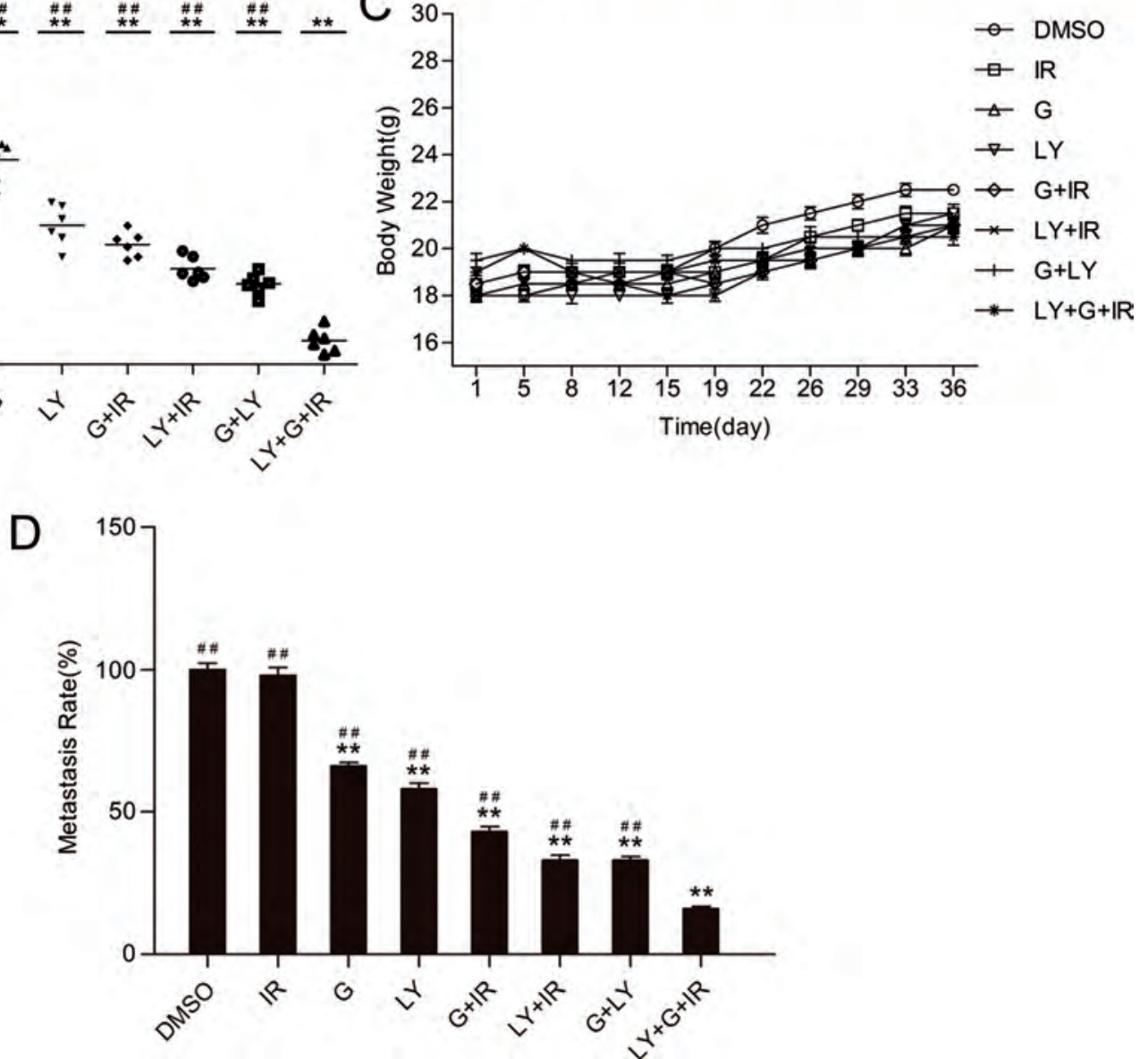

Figure 4. The effect of different treatments on tumor growth and tumor metastasis in vivo. A) All 7 different kinds of treatments appeared obvious inhibition on tumor growth in nude mice models compared with DMSO group, respectively. B) All 7 different kinds of treatments appeared statistically significant inhibition on tumor growth in nude mice models compared with DMSO group, respectively ( ${ }^{* *} p<0.01$ ), and the effect of LY+G+IR group was the most efficient $(\# \# p<0.01)$. C) The changes of nude mice' body weights in 8 groups. $D$ ) The comparison of the metastasis rates in 8 groups (vs DMSO group: ${ }^{* *} p<0.01$, vs LY+G+IR group: \# \#p<0.01). 


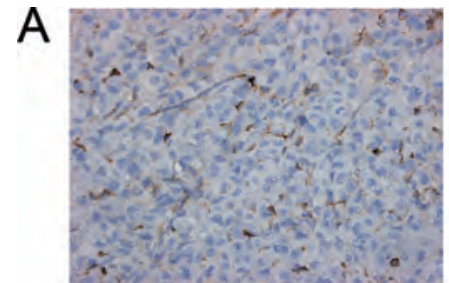

DMSO

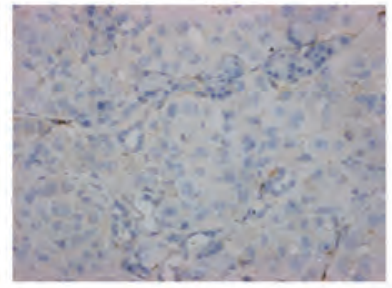

G+IR

B

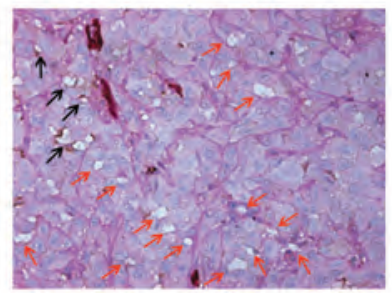

DMSO

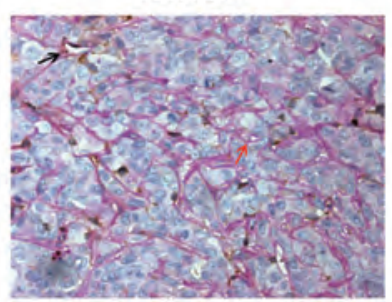

G+IR

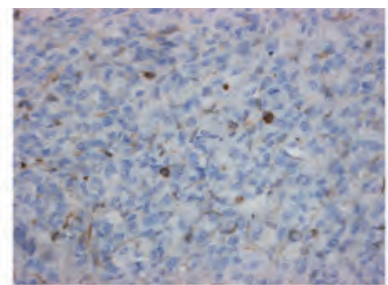

IR

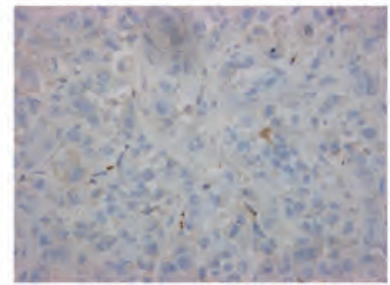

$\mathrm{LY}+\mathrm{IR}$

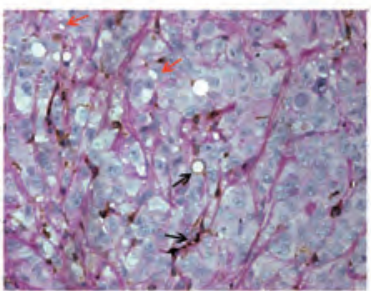

IR

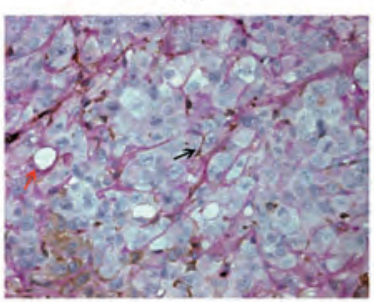

$L Y+I R$

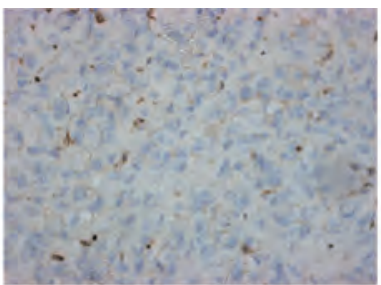

G

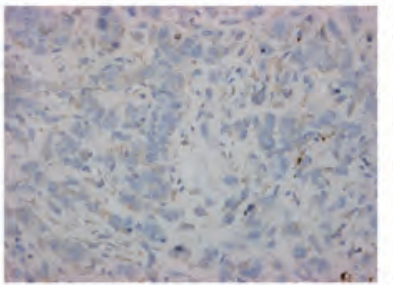

G+LY

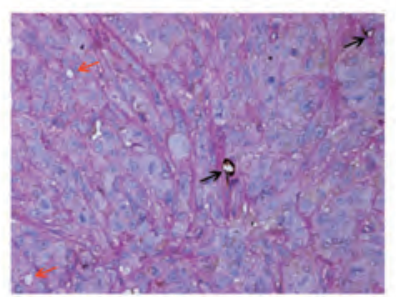

G

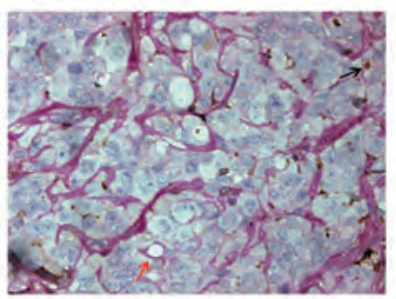

G+LY

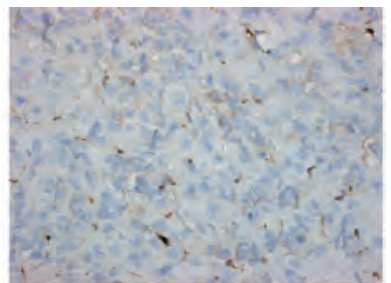

LY

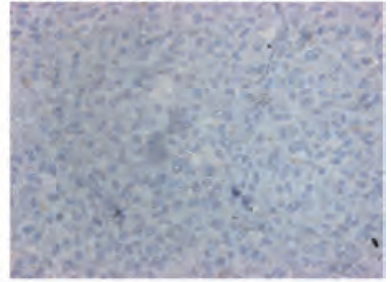

$L Y+G+I R$

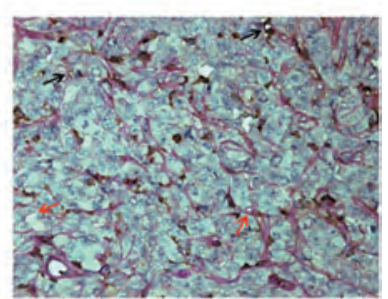

LY

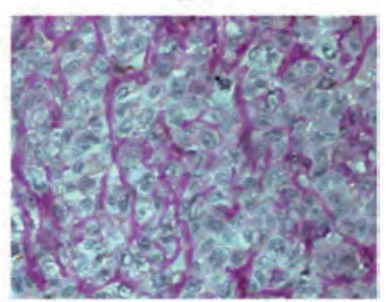

$L Y+G+I R$
C

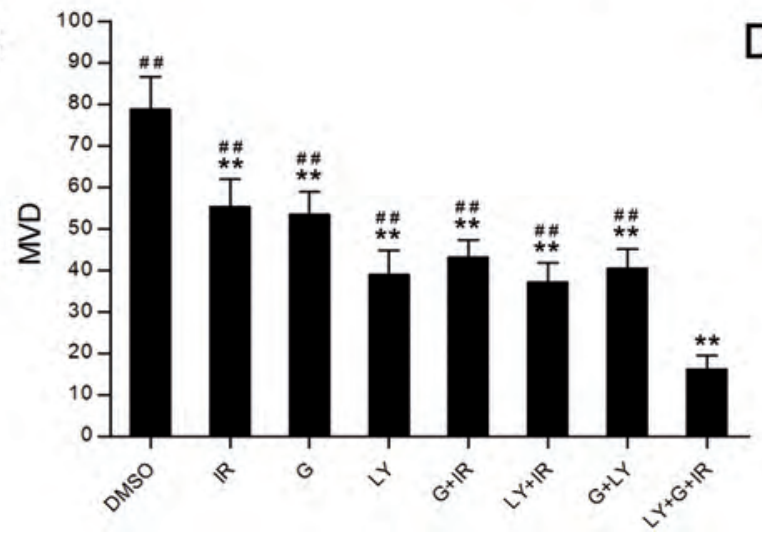

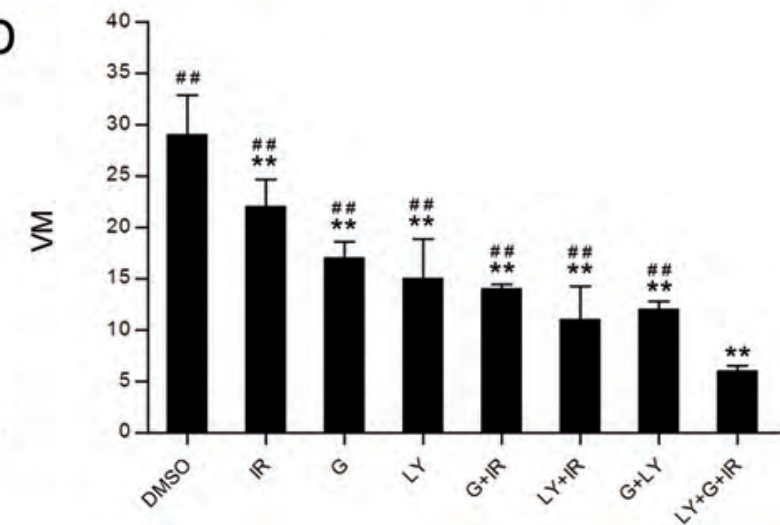

Figure 5. The effect of different treatments on MVD and VMD in vivo. A) The anti-CD31 immunostaining of microvessels in orthotopic Panc-1 xenografts $(\times 100)$. B) The CD31/ PAS double staining of VM in orthotopic Panc-1 xenografts $(\times 100)$; microvessel (black arrow) and VM (red arrow) could be seen in these panels. C) and D) All 7 different kinds of treatments decreased MVD and VMD compared with DMSO group, respectively $\left({ }^{* *} p<0.01\right)$, while $\mathrm{LY}+\mathrm{G}+\mathrm{IR}$ group displayed the greatest reduction in MVD and VMD $(\#$ \# $<0.01)$. 
structure different from angiogenesis that exists in some highly aggressive tumors, it should be considered to develop novel therapeutic regimens and antivascular therapeutic agents that target both angiogenesis and VM, in particular, anti-VM therapy when in anticancer treatment of some highly aggressive cancers with VM. In this study, we explored the effect of LY294002 and gemcitabine hydrochloride combined with IR on both angiogenesis (MVD) and VM (VMD) in pancreatic cancer. Our study indicated that the novel therapeutic regimen showed obvious inhibition on both MVD and VMD in orthotopic Panc-1 xenografts.

Molecular mechanisms underlying VM displayed by highly aggressive cancer cells such as Panc- 1 cells remain poorly understood. Hence, it would be an important event to understand the key molecular events regulating VM in human pancreatic cancer, which could provide potential targets for new therapies of pancreatic cancer. Recently, several studies have shown that some key molecules play crucial roles in
VM formation, including PI3K, MMPs, Ln-5 $\gamma^{2}$ chain [10, $13,27,32-34]$, etc. PI3Ks constitute a family of lipid kinases implicated in signal transduction through tyrosine kinase receptors and heterotrimeric $\mathrm{G}$ protein-linked receptors. PI3Ks are heterodimers made up of four different $110-\mathrm{kDa}$

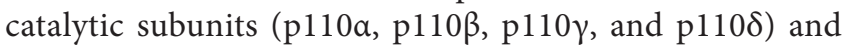
a smaller regulatory subunit. The PI3K signaling pathway plays an integral role in many important cellular processes, including survival, proliferation, differentiation, metabolism and motility, in a variety of cell types [35]. One of the best characterized targets of PI3K lipid products is the serine/ threonine protein kinase Akt [36]. Because PI3K plays a biological role mainly through activation of Akt, we usually detect the activation of PI3K by detecting the expression of p-Akt. Hess AR et al [33] have reported that the VM formation of melanoma is abolished with decreased MMP-2 and MT1-MMP activity after using specific inhibitors of PI3K. Furthermore, the cleavage of $\operatorname{Ln}-5 \gamma 2$ chain was blocked.
A

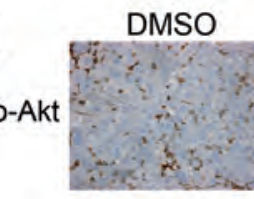

Akt

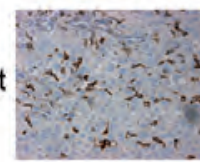

MMP-2

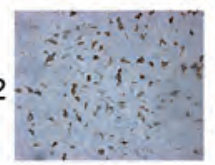

IR
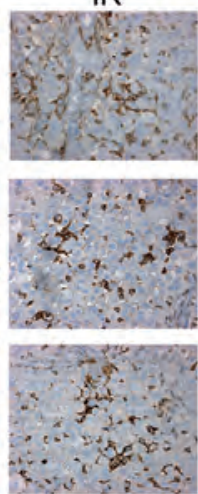

G
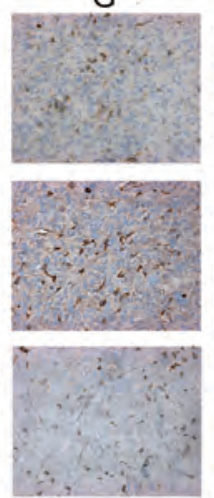

LY
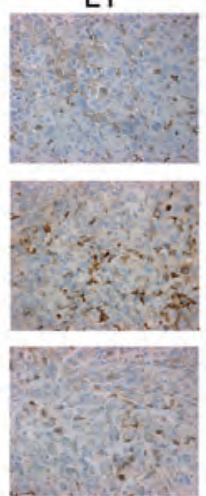

$\mathrm{G}+\mathrm{IR}$
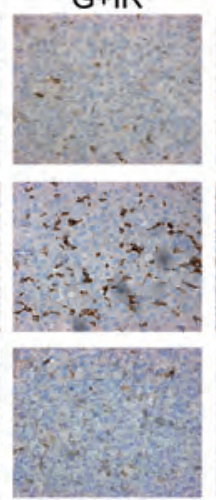

$L Y+I R$
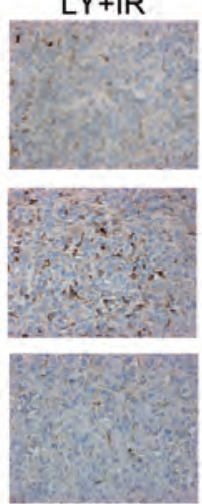

$\mathrm{G}+\mathrm{LY}$
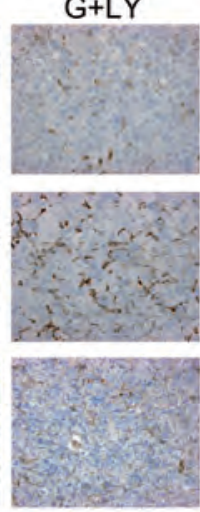

$L Y+G+I R$
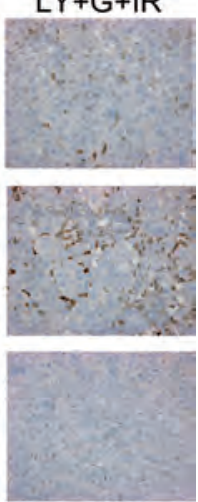
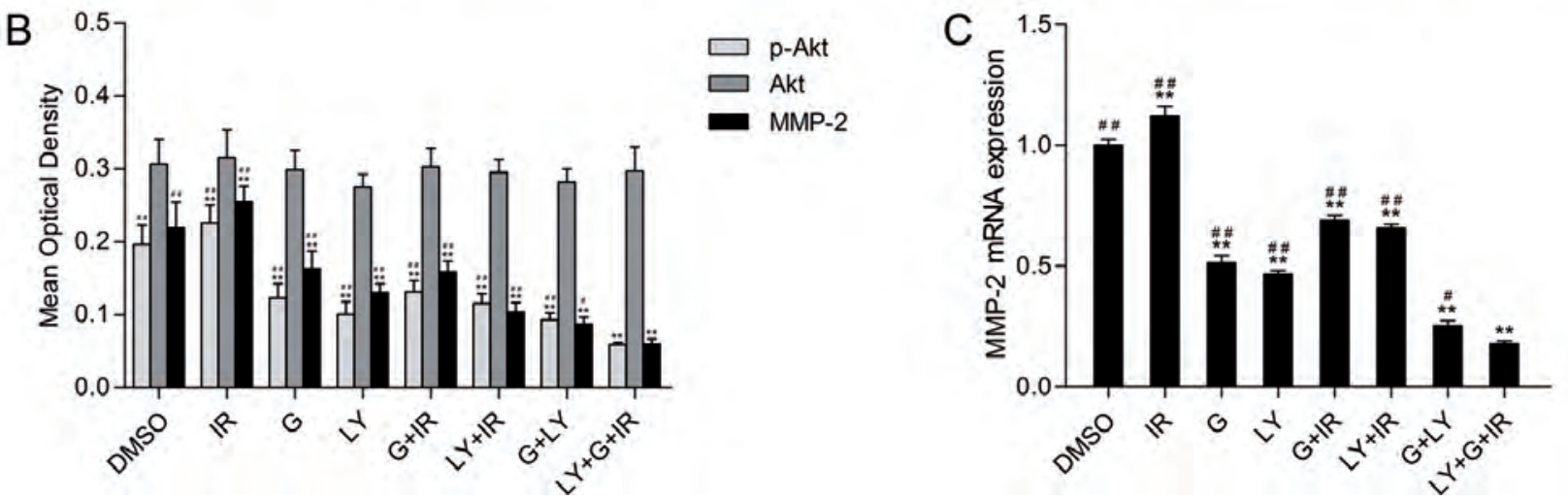

Figure 6. The effect of different treatments on the expressions of p-Akt, Akt and MMP-2 proteins and the expression of MMP-2 mRNA in vivo. A) The anti-p-Akt, anti-Akt and anti-MMP-2 immunostaining of orthotopic Panc-1 xenografts in 8 groups $(\times 100)$. B $)$ The expressions of Akt proteins in 8 groups were consistent, the expressions of p-Akt and MMP-2 proteins in IR group were statistically significant increased compared with DMSO group, while the expressions of these markers in the remaining 6 different kinds of treatment groups were statistically significant downregulated compared with DMSO group, respectively $\left({ }^{* *} p<0.01\right), \mathrm{LY}+\mathrm{G}+\mathrm{IR}$ group displayed the greatest inhibition on the expressions of $p$-Akt and MMP-2 proteins ( $\# p<0.05$, or $\# \# p<0.01)$. C) IR promoted the expression of MMP-2 mRNA in vivo, while the remaining 6 different kinds of treatments statistically significant suppressed the expression of MMP-2 mRNA compared with DMSO group, respectively $\left({ }^{* *} p<0.01\right)$, and LY+G+IR group showed the strongest inhibitory effect $(\# p<0.05$ and $\# \# p<0.01)$. 
Matrix metalloproteinases (MMPs), divided into soluble MMPs and MT-MMP, belong to a family of extracellular matrix degrading proteinases. Owing to their matrix-degrading abilities and high expression in advanced tumors, MMPs are originally implicated in invasion, metastasis and angiogenesis during cancer progression [37-39]. Specifically, MT1-MMP and MMP-2 are identified as important mediators of tumor invasion, metastasis, angiogenesis and tumor cell VM [27, 40]. Recent studies have indicated that MMP-2 and MT1MMP appear to play a key role in the development of VM by aggressive melanoma and ovarian cancer cells in 3-D culture $[33,34]$. It was reported that MMPs were all more highly expressed in aggressive melanoma with VM compared with poorly aggressive melanoma with absence of VM [41]. The Ln-5 $\gamma 2$ chains in the extracellular matrix can promote VM formation [27, 32]. PI3K can directly regulate MT1-MMP activity which promotes the conversion of pro-MMP-2 into its active conformation. Active MMP- 2 may then promote the cleavage of $\operatorname{Ln}-5 \gamma 2$ chains into $5 \gamma 2^{\prime}$ and $5 \gamma 2 x$ fragments. The deposition of these fragments may result in increased migration, invasion and VM formation [27, 32]. Our study indicated that PI3K specific inhibitor LY294002 inhibited the formation of VM in both Panc-1 cells' 3-D matrices in vitro and orthotopic Panc-1 xenografts in vivo through inhibiting the activation of PI3K, and then suppressed the activation of MMP-2. Furthermore, LY294002 and gemcitabine hydrochloride combined with IR better inhibited cell migration, VM formation and MMP-2 mRNA expression of Panc- 1 cells in vitro, and we also proved that the novel therapeutic regimen better inhibited tumor growth, tumor metastasis and VM formation of orthotopic Panc-1 xenografts by suppressing the PI3-K/MMPs/Ln-5 $\gamma 2$ signaling pathway in vivo. Our current study is among the first to provide preliminary evidence for the use of the novel therapeutic regimen LY294002 and gemcitabine hydrochloride combined with IR for treatment of pancreatic cancer.

PI3K is critical in many important physiological activities [35]. Suppressing the activity of PI3K can inhibit tumor growth; however, the impact of PI3K inhibitor on biological behavior of normal tissues should not be ignored. Recently, several studies [42-44] have demonstrated that hematological malignancies of B cells, including chronic lymphocytic leukemia, indolent non-Hodgkin lymphoma, and mantle cell lymphoma, have constitutively active PI3K/Akt signaling pathways and respond to an oral PI $3 \mathrm{~K} \delta$-specific inhibitor, CAL-101, which is already being used in clinic. It's essential to develop more PI3K selective inhibitors to fight against various tumors.

One of contributors to the limited benefit of radiotherapy is IR-enhanced tumor invasiveness [16], however, its mechanism is still not clear. Some researchers have demonstrated that IR can enhance the invasiveness of tumor cells by promoting the expression of genes that are related to malignant tumor metastasis or by activating some signaling pathways that are associated with malignant tumor metastasis. Qiao Q et al
[45] have demonstrated that apoptosis in human Burkitt's lymphoma cells that were treated with IR can be enhanced by blocking IR-induced activation of the PI3K/Akt pathway by LY294002 or SH-5. Besides, Li X et al [16] have shown that invasiveness of IR-survived lung cancer cells can be enhanced by intergrin $\alpha 2 \beta 1$ and EGFR cooperatively, and the invasiveness was mediated by the PI3K/Akt signaling pathway partly, which might serve as alternative targets for radiosensitization. Our study demonstrated that IR inhibited the tumor growth of orthotopic Panc-1 xenograft models significantly in vivo, whereas it improved the expression of p-Akt in tumor tissues. What's more, IR was ineffective in suppressing distant metastasis of pancreatic cancer in orthotopic Panc-1 xenograft models in vivo. It was proved that the PI3K/Akt pathway was activated by IR in orthotopic Panc-1 xenografts. This activation could be eliminated by combining IR with LY294002 and/or gemcitabine hydrochloride. Recently, Yao $\mathrm{H}$ et al [46] have suggested that systemic inhibition of $\alpha 5 \beta 1$-mediated invasion could reduce IR-induced pancreatic cancer cell invasion, thereby improving the efficacy of IR. Still, further studies are needed to clarify the mechanism of IR-induced pancreatic cancer cell invasion.

\section{References}

[1] SIEGEL R, NAISHADHAM D AND JEMAL A. Cancer statistics, 2012. CA Cancer J Clin 2012; 62: 10-29. http://dx.doi. org/10.3322/caac. 20138

[2] BILIMORIA KY, BENTREM DJ, KO CY, STEWART AK, WINCHESTER DP, et al. National failure to operate on early stage pancreatic cancer. Ann Surg 2007; 246: 173-180. http:// dx.doi.org/10.1097/SLA.0b013e3180691579

[3] DUONG HQ, KIM HJ, KANG HJ, SEONG YS AND BAE I. ZSTK474, a PI3K inhibitor, suppresses proliferation and sensitizes human pancreatic adenocarcinoma cells to gemcitabine. Oncol Rep 2012; 27: 182-188.

[4] CHATTERJEE M, BEN-JOSEF E, THOMAS DG, MORGAN MA, ZALUPSKI MM, et al. Caveolin-1 is Associated with Tumor Progression and Confers a Multi-Modality Resistance Phenotype in Pancreatic Cancer. Sci Rep 2015; 5: 10867. http:// dx.doi.org/10.1038/srep10867

[5] MANiOTIS AJ, FOLBERG R, HESS A, SEFTOR EA, GARDNER LM, et al. Vascular channel formation by human melanoma cells in vivo and in vitro: vasculogenic mimicry. Am J Pathol 1999; 155: 739-752. http://dx.doi.org/10.1016/ $\underline{\text { S0002-9440(10)65173-5 }}$

[6] GUZMAN G, COTLER SJ, LIN AY, MANIOTIS AJ AND FOLBERG R. A pilot study of vasculogenic mimicry immunohistochemical expression in hepatocellular carcinoma. Arch Pathol Lab Med 2007; 131: 1776-1781.

[7] SUN B, QIE S, ZHANG S, SUN T, ZHAO X, et al. Role and mechanism of vasculogenic mimicry in gastrointestinal stromal tumors. Hum Pathol 2008; 39: 444-451. http://dx.doi. org/10.1016/j.humpath.2007.07.018

[8] PAULIS YW, SOETEKOUW PM, VERHEUL HM, TJANHEIJNEN VC AND GRIFFIOEN AW. Signalling pathways 
in vasculogenic mimicry. Biochim Biophys Acta 2010; 1806: 18-28. http://dx.doi.org/10.1016/j.bbcan.2010.01.001

[9] XU XD, YANG L, ZHENG LY, PAN YY, CAO ZF, et al. Suberoylanilide hydroxamic acid, an inhibitor of histone deacetylase, suppresses vasculogenic mimicry and proliferation of highly aggressive pancreatic cancer PaTu8988 cells. BMC Cancer 2014; 14: 373. http://dx.doi.org/10.1186/14712407-14-373

[10] GUO JQ, ZHENG QH, CHEN H, CHEN L, XU JB, et al. Ginsenoside $\operatorname{Rg} 3$ inhibition of vasculogenic mimicry in pancreatic cancer through downregulation of VEcadherin/ EphA2/MMP9/MMP2 expression. Int J Oncol 2014; 45: 1065-1072.

[11] VARTANIAN AA. Signaling pathways in tumor vasculogenic mimicry. Biochemistry (Mosc) 2012; 77: 1044-1055. http:// dx.doi.org/10.1134/S000629791209012X

[12] CHEN LX, HE YJ, ZHAO SZ, WU JG, WANG JT, et al. Inhibition of tumor growth and vasculogenic mimicry by curcumin through down-regulation of the EphA2/PI3K/ MMP pathway in a murine choroidal melanoma model. Cancer Biol Ther 2011; 11: 229-235. http://dx.doi.org/10.4161/ cbt.11.2.13842

[13] ZHANG JT, SUN W, ZHANG WZ, GE CY, LIU ZY, et al. Norcantharidin inhibits tumor growth and vasculogenic mimicry of human gallbladder carcinomas by suppression of the PI3-K/ MMPs/Ln-5gamma2 signaling pathway. BMC Cancer 2014; 14: 193. http://dx.doi.org/10.1186/1471-2407-14-193

[14] LIANG Y, HUANG M, LI J, SUN X, JIANG X, et al. Curcumin inhibits vasculogenic mimicry through the downregulation of erythropoietin-producing hepatocellular carcinoma-A2, phosphoinositide 3-kinase and matrix metalloproteinase-2. Oncol Lett 2014; 8: 1849-1855.

[15] WERNER J, COMBS SE, SPRINGFELD C, HARTWIG W, HACKERT T, et al. Advanced-stage pancreatic cancer: therapy options. Nat Rev Clin Oncol 2013; 10: 323-333. http://dx.doi. org/10.1038/nrclinonc.2013.66

[16] LI X, ISHIHARA S, YASUDA M, NISHIOKA T, MIZUTANI $\mathrm{T}$, et al. Lung cancer cells that survive ionizing radiation show increased integrin alpha2beta1- and EGFR-dependent invasiveness. PLoS One 2013; 8: e70905. http://dx.doi.org/10.1371/ journal.pone.0070905

[17] KLEEFF J, FRIESS H AND BUCHLER MW. Neoadjuvant therapy for pancreatic cancer. Br J Surg 2007; 94: 261-262. http://dx.doi.org/10.1002/bjs.5737

[18] BONDAR VM, SWEENEY-GOTSCH B, ANDREEFF M, MILLS GB AND MCCONKEY DJ. Inhibition of the phosphatidylinositol 3'-kinase-AKT pathway induces apoptosis in pancreatic carcinoma cells in vitro and in vivo. Mol Cancer Ther 2002; 1: 989-997.

[19] GIRARD N, MORNEX F, BOSSARD N, YCHOU M, CHAUFFERT B, et al. Estimating optimal dose of twiceweekly gemcitabine for concurrent chemoradiotherapy in unresectable pancreatic carcinoma: mature results of GEMRT-01 Phase I trial. Int J Radiat Oncol Biol Phys 2010; 77: 1426-1432. http://dx.doi.org/10.1016/j.ijrobp.2009.06.053

[20] SHIBUYA K, OYA N, FUJII T, DOI R, NAKAMURA A, et al. Phase II study of radiation therapy combined with weekly low-dose gemcitabine for locally advanced, unresectable pancreatic cancer. Am J Clin Oncol 2011; 34: 115-119.

[21] VLAHOS CJ, MATTER WF, HUI KY AND BROWN RF. A specific inhibitor of phosphatidylinositol 3-kinase, 2-(4morpholinyl)-8-phenyl-4H-1-benzopyran-4-one (LY294002). J Biol Chem 1994; 269: 5241-5248.

[22] MA WW, MESSERSMITH WA, DY GK, WEEKES CD, WHITWORTH A, et al. Phase I study of Rigosertib, an inhibitor of the phosphatidylinositol 3-kinase and Polo-like kinase 1 pathways, combined with gemcitabine in patients with solid tumors and pancreatic cancer. Clin Cancer Res 2012; 18: 2048-2055. http://dx.doi.org/10.1158/1078-0432. CCR-11-2813

[23] SOOD AK, SEFTOR EA, FLETCHER MS, GARDNER LM, HEIDGER PM, et al. Molecular determinants of ovarian cancer plasticity. Am J Pathol 2001; 158: 1279-1288. http:// dx.doi.org/10.1016/S0002-9440(10)64079-5

[24] GRAESER R, BORNMANN C, ESSER N, ZIROLI V, JANTSCHEFF P, et al. Antimetastatic effects of liposomal gemcitabine and empty liposomes in an orthotopic mouse model of pancreatic cancer. Pancreas 2009; 38: 330-337. http:// dx.doi.org/10.1097/MPA.0b013e31819436e6

[25] ZHANG Y, SUN B, ZHAO X, LIU Z, WANG X, et al. Clinical significances and prognostic value of cancer stem-like cells markers and vasculogenic mimicry in renal cell carcinoma. J Surg Oncol 2013; 108: 414-419. http://dx.doi.org/10.1002/ jso.23402

[26] WEIDNER N, FOLKMAN J, POZZA F, BEVILACQUA P, ALLRED EN, et al. Tumor angiogenesis: a new significant and independent prognostic indicator in early-stage breast carcinoma. J Natl Cancer Inst 1992; 84: 1875-1887. http:// dx.doi.org/10.1093/jnci/84.24.1875

[27] SEFTOR RE, SEFTOR EA, KOSHIKAWA N, MELTZER PS, GARDNER LM, et al. Cooperative interactions of laminin 5 gamma2 chain, matrix metalloproteinase-2, and membrane type-1-matrix/metalloproteinase are required for mimicry of embryonic vasculogenesis by aggressive melanoma. Cancer Res 2001; 61: 6322-6327.

[28] SEFTOR RE, HESS AR, SEFTOR EA, KIRSCHMANN DA, HARDY KM, et al. Tumor cell vasculogenic mimicry: from controversy to therapeutic promise. Am J Pathol 2012; 181: 1115-1125. http://dx.doi.org/10.1016/j.ajpath.2012.07.013

[29] CHEN HX AND CLECK JN. Adverse effects of anticancer agents that target the VEGF pathway. Nat Rev Clin Oncol 2009; 6: 465-477. http://dx.doi.org/10.1038/ nrclinonc.2009.94

[30] VAN DER SCHAFT DW, SEFTOR RE, SEFTOR EA, HESS AR, GRUMAN LM, et al. Effects of angiogenesis inhibitors on vascular network formation by human endothelial and melanoma cells. J Natl Cancer Inst 2004; 96: 1473-1477. http:// dx.doi.org/10.1093/jnci/djh267

[31] HIGA GM AND ABRAHAM J. Biological mechanisms of bevacizumab-associated adverse events. Expert Rev Anticancer Ther 2009; 9: 999-1007. http://dx.doi.org/10.1586/ $\underline{\text { era. } 09.68}$

[32] SEFTOR RE, SEFTOR EA, KIRSCHMANN DA AND HENDRIX MJ. Targeting the tumor microenvironment with 
chemically modified tetracyclines: inhibition of laminin 5 gamma2 chain promigratory fragments and vasculogenic mimicry. Mol Cancer Ther 2002; 1: 1173-1179.

[33] HESS AR, SEFTOR EA, SEFTOR RE AND HENDRIX MJ. Phosphoinositide 3-kinase regulates membrane Type 1-matrix metalloproteinase (MMP) and MMP-2 activity during melanoma cell vasculogenic mimicry. Cancer Res 2003; 63: 4757-4762.

[34] SOOD AK, FLETCHER MS, COFFIN JE, YANG M, SEFTOR EA, et al. Functional role of matrix metalloproteinases in ovarian tumor cell plasticity. Am J Obstet Gynecol 2004; 190: 899-909. http://dx.doi.org/10.1016/j.ajog.2004.02.011

[35] LINK W, ROSADO A, FOMINAYA J, THOMAS JE AND CARNERO A. Membrane localization of all class I PI 3-kinase isoforms suppresses c-Myc-induced apoptosis in Rat1 fibroblasts via Akt. J Cell Biochem 2005; 95: 979-989. http://dx.doi. org/10.1002/jcb.20479

[36] MARTELLI AM, FAENZA I, BILLI AM, MANZOLI L, EVANGELISTI C, et al. Intranuclear 3'-phosphoinositide metabolism and Akt signaling: new mechanisms for tumorigenesis and protection against apoptosis? Cell Signal 2006; 18: 1101-1107. http://dx.doi.org/10.1016/j.cellsig.2006.01.011

[37] MCCAWLEY LJ AND MATRISIAN LM. Matrix metalloproteinases: multifunctional contributors to tumor progression. Mol Med Today 2000; 6: 149-156. http://dx.doi.org/10.1016/ S1357-4310(00)01686-5

[38] NOEL A, GILLES C, BAJOU K, DEVY L, KEBERS F, et al. Emerging roles for proteinases in cancer. Invasion Metastasis 1997; 17: 221-239.

[39] STETLER-STEVENSON WG. Matrix metalloproteinases in angiogenesis: a moving target for therapeutic intervention. J Clin Invest 1999; 103: 1237-1241. http://dx.doi.org/10.1172/ ICI6870

[40] CHANG C AND WERB Z. The many faces of metalloproteases: cell growth, invasion, angiogenesis and metastasis.
Trends Cell Biol 2001; 11: S37-43. http://dx.doi.org/10.1016/ S0962-8924(01)82222-4

[41] HENDRIX MJ, SEFTOR EA, KIRSCHMANN DA, QUARANTA V AND SEFTOR RE. Remodeling of the microenvironment by aggressive melanoma tumor cells. Ann N Y Acad Sci 2003; 995: 151-161. http://dx.doi.org/10.1111/ j.1749-6632.2003.tb03218.x

[42] LANNUTTI BJ, MEADOWS SA, HERMAN SE, KASHISHIAN A, STEINER B, et al. CAL-101, a p110delta selective phosphatidylinositol-3-kinase inhibitor for the treatment of B-cell malignancies, inhibits PI3K signaling and cellular viability. Blood 2011; 117: 591-594. http://dx.doi.org/10.1182/ blood-2010-03-275305

[43] HOELLENRIEGEL J, MEADOWS SA, SIVINA M, WIERDA WG, KANTARJIAN H, et al. The phosphoinositide 3'-kinase delta inhibitor, CAL-101, inhibits B-cell receptor signaling and chemokine networks in chronic lymphocytic leukemia. Blood 2011; 118: 3603-3612. http://dx.doi.org/10.1182/blood-2011 $\underline{-05-352492}$

[44] MEADOWS SA, VEGA F, KASHISHIAN A, JOHNSON D, DIEHL V, et al. PI3Kdelta inhibitor, GS-1101 (CAL-101), attenuates pathway signaling, induces apoptosis, and overcomes signals from the microenvironment in cellular models of Hodgkin lymphoma. Blood 2012; 119: 1897-1900. http:// dx.doi.org/10.1182/blood-2011-10-386763

[45] QIAO Q, JIANG Y AND LI G. Inhibition of the PI3K/ AKT-NF-kappaB pathway with curcumin enhanced radiation-induced apoptosis in human Burkitt's lymphoma. J Pharmacol Sci 2013; 121:247-256. http://dx.doi.org/10.1254/ jphs.12149FP

[46] YAO H, ZENG ZZ, FAY KS, VEINE DM, STASZEWSKI ED, et al. Role of alpha(5)beta(1) Integrin Up-regulation in Radiation-Induced Invasion by Human Pancreatic Cancer Cells. Transl Oncol 2011; 4: 282-292. http://dx.doi.org/10.1593/ tlo.11133 